\title{
Criptococosis en pacientes inmunosuprimidos sin infección por VIH/SIDA: un nuevo problema clínico en Chile
}

\author{
Alberto Fica, Andrés Soto, Jeannette Dabanch P, Jorge Pinilla y Lorena Porte
}

\section{Cryptococcal infections in non-HIV infected patients: a new clinical problem in Chile}

Cryptococcal infections are classically associated to HIV/AIDS patients without therapy, but its presence among other immunosuppressed patients is less recognized. We report 3 lethal cases in non HIV-patients. Two of them presented with meningitis associated to renal transplant or corticosteroid use and, the third, with a necrotic skin infection in the context of progressive liver cirrhosis. In the former two patients, meningeal infection was suspected late, and in the latter, the diagnosis was established postmortem. Cryptococcal infections in non-HIV immunosupressed patients can affect different sites, are suspected late and have a high case-fatality ratio.

Key words: Cryptococcus, meningitis, liver cirrhosis, peritonitis, immunosuppression.

Palabras clave: Cryptococcus, meningitis, cirrosis hepática, peritonitis, inmunosupresión.

\section{Introducción}

$C$ ryptococcus neoformans alcanzó alta notoriedad con el advenimiento de la pandemia de SIDA. La disponibilidad de terapia anti-retroviral altamente efectiva redujo notoriamente la frecuencia en los países desarrollados gracias a la restauración del sistema inmu$n e^{1}$. En países en vías en desarrollo sigue constituyendo una causa de hospitalización ${ }^{2}$. En claro contraste a su asociación con pacientes con infección por VIH/SIDA, las infecciones por C. neoformans se presentaban con baja frecuencia en otro tipo de pacientes inmunosuprimidos. El aumento de la población de pacientes con inmunosupresión asociada a trasplante de órganos y tejidos o por fármacos inmunosupresores como corticosteroides, ha permitido el aumento de la frecuencia de infecciones por ese microorganismo. El propósito de este trabajo es comunicar tres casos de infección criptocócica diagnosticados entre los años 2007 y 2012 en un hospital general en pacientes con inmunosupresión no asociada a infección por VIH/SIDA.

Los casos fueron identificados a través del registro de pacientes atendidos por el Servicio de Infectología del Hospital Militar de Santiago de Chile, un hospital de tipo general que atiende a los militares en servicio activo, en retiro, sus cargas familiares y población general.

Este trabajo fue aprobado por el Comité de Ética del hospital.

\section{Caso 1}

Mujer, 69 años (Tabla 1). En abril de 2010 se estudió por presentar un cuadro caracterizado por baja de peso, celulitis en una extremidad inferior, síndrome depresivo y anemia. Se estableció el diagnóstico de vasculitis renal c-ANCA/PR3 $(+)$, con una velocidad de sedimentación elevada $(100 \mathrm{~mm} / \mathrm{h})$. Esta vasculitis no se asoció a hipertensión arterial, pero sí a falla renal moderada. Inició corticosteroides en dosis inmunosupresora en mayo de 2010, asociados, en un primer momento, a ciclofosfamida. El tratamiento de la vasculitis logró revertir parcialmente la falla renal, la anemia y el compromiso ponderal. La dosis de prednisona fue disminuida progresivamente hasta $10 \mathrm{mg} /$ día. En julio de 2010 se incorporó al tratamiento azatioprina.

En agosto de 2011 fue hospitalizada en el Servicio de Medicina de nuestra institución por síntomas urinarios bajos, fiebre y cefalea intensa durante 7 días, recibiendo $10 \mathrm{mg}$ de prednisona y una dosis de azatioprina no precisada. Entre los exámenes de laboratorio solicitados destacaron un sedimento de orina con signos inflamatorios, hemograma con leucocitos de $7.000 / \mathrm{mm}^{3}$ y $88,8 \%$ de neutrófilos, aumento de la proteína $\mathrm{C}$ reactiva (37 mg/L), creatininemia elevada $(1,5 \mathrm{mg} / \mathrm{dL})$ y una TAC cerebral normal. Se interpretó como una posible infección urinaria, iniciando empíricamente tratamiento antimicrobiano con ceftriaxona desde el segundo día de hospitalización. El esquema se mantuvo al detectarse Escherichia coli en un urocultivo. La radiografía de tórax no mostró infiltrados, los hemocultivos fueron negativos, un examen oftalmológico no mostró signos que sugirieran hipertensión endocraneal y los estudios tomográfico de abdomen y pelvis y ecocardiografía fueron normales. No obstante, la paciente persistió febril, con cefalea intermitente y compromiso de conciencia fluctuante. Desarrolló
Hospital Militar de Santiago, Santiago, Chile. Servicio de Infectología (AF, AS, JDP). Laboratorio Clínico (LP). Servicio de Imagenología (MCS). Servicio de Anatomía Patológica (JP) Clínica Alemana, Santiago Chile. Laboratorio Clínico (LP) Universidad de los Andes, Santiago, Chile. (JDP)

Los autores declaran no presentar conflictos de interés. Financiamiento: no hubo.

Recibido: 18 de julio de 2014 Aceptado: 20 de octubre de 2014

Correspondencia a: Alberto Fica Cubillo albertofica@gmail.com 
hiponatremia marcada $\left(\mathrm{Na}^{+} 116 \mathrm{mEq} / \mathrm{L}\right)$ a los 20 días del ingreso y luego aparición de signos meníngeos, lo que hizo plantear una infección del SNC. Se solicitaron nuevos hemocultivos y estudio de LCR, cuyo análisis citoquímico resultó normal y el cultivo bacteriano fue negativo. No se solicitó tinción de tinta china ni test rápido para la detección de $C$. neoformans. Debido a la mala evolución clínica de la paciente, se repitió el estudio de LCR. Al cuarto día de incubación del primer cultivo de LCR (en agar sangre y chocolate, $35^{\circ} \mathrm{C}$, atmósfera con $5 \% \mathrm{CO}_{2}$ ) se obtuvo crecimiento de C. neoformans. En la segunda muestra de LCR, se identificaron levaduras en la tinción con tinta china, en paralelo al hallazgo de una leve pleocitosis ( 8 céls $/ \mathrm{mm}^{3}$, de tipo mononuclear) sin anormalidades en la proteinorraquia ni glucorraquia. Se trató con voriconazol por vía IV utilizando una dosis de carga (6 mg/kg cada $12 \mathrm{~h}$ ) y luego dosis de mantención ( $4 \mathrm{mg} / \mathrm{kg}$ cada $12 \mathrm{~h}$ ), sin falla renal en ese momento. Se optó por este compuesto por la gravedad del paciente (ver Discusión), dificultades para conseguir anfotericina $\mathrm{B}$ desoxicolato o liposomal y riesgo de toxicidad renal en una paciente con deterioro basal de la creatininemia. A las 24 h de terapia antifúngica fue trasladada a la Unidad de Cuidados Intensivos por presentar depresión respiratoria, bradicardia extrema y luego asistolía. Falleció al tercer día de tratamiento antifúngico.

\section{Caso 2}

Mujer de 49 años (Tabla 1), con antecedentes de diabetes mellitus, epilepsia y trasplante renal secundario a nefropatía por IgA, en terapia inmunosupresora con prednisona (10 mg/día), tacrolimus ( $9 \mathrm{mg} /$ día) y micofenolato (1,5 g/día). La paciente fue hospitalizada al séptimo mes del trasplante en la Unidad de Cuidados Intermedios de nuestro hospital (año 2007) por un cuadro caracterizado por fiebre, cefalea frontal, dolor maxilar bilateral y leucocitosis de $17.000 / \mathrm{mm}^{3}$. Estas manifestaciones fueron interpretadas como una rinosinusitis aguda y se inició tratamiento con moxifloxacina. Su creatininemia era de 2,6 $\mathrm{mg} / \mathrm{dL}$. Evolucionó con fiebre y persistencia de la cefalea, hiponatremia $\left(\mathrm{Na}^{+} 123 \mathrm{mEq} / \mathrm{L}\right)$ e inestabilidad metabólica. Los hemocultivos fueron negativos. Una semana después del ingreso, presentó temblor generalizado, compromiso de conciencia cuantitativo, somnolencia, desorientación y lentitud. Una RM cerebral demostró mastoiditis y sinusitis etmoidal. Un primer estudio de LCR indicó proteinorraquia de $219 \mathrm{mg} / \mathrm{dL}$, glucorraquia de $2 \mathrm{mg} / \mathrm{dL}$, pleocitosis de 160 células $/ \mathrm{mm}^{3}$ de predominio mononuclear $(85 \%)$ y un valor ADA de 25,9 U/L. El estudio complementario del LCR mostró un resultado negativo de las RCP para Mycobacterium tuberculosis, CMV, virus Epstein Barr, herpes simplex virus 1-2 y enterovirus. Las pruebas de aglutinación en LCR para Streptococcus pneumoniae, Neisseria meningitidis y Haemophilus influenzae tipo b también fueron negativas. No se solicitó cultivo de hongos del LCR, pero el test de tinta China para C. neoformans fue negativo y el antígeno para $C$. neoformans fue derivado a un laboratorio externo. El cuadro clínico fue interpretado como una probable tuberculosis (TBC) meníngea por su equipo tratante, iniciando terapia empírica. La paciente evolucionó de forma tórpida con mayor compromiso de conciencia y convulsiones requiriendo ingreso a la Unidad de Cuidados Intensivos y conexión a ventilación mecánica. La TAC cerebral mostró crecimiento del tercer ventrículo por lo que se instaló una derivación ventricular externa, sin que se observara reversión en el compromiso de conciencia. Se repitió el estudio de LCR, obteniéndose una tinción de tinta china positiva y crecimiento de $C$. neoformans a las $24 \mathrm{~h}$ de incubación en placa de agar y el antígeno para $C$. neoformans obtenido en la primera punción lumbar fue informado positivo. La RM cerebral detectó lesiones isquémicas en los ganglios basales con necrosis cortical laminar fronto-insular e hidrocefalia moderada difusa. Se inició tratamiento con anfotericina B desoxicolato $50 \mathrm{mg} /$ día. La paciente evolucionó con deterioro clínico progresivo y falleció a los 62 días de ingreso y 22 días de terapia con anfotericina $\mathrm{B}$, apoyada en los últimos días con fluconazol $600 \mathrm{mg} /$ día.

\section{Caso 3}

Hombre de 58 años de edad (Tabla 1), portador de cirrosis hepática de etiología no precisada, Child C. Antecedente de cinco hospitalizaciones desde octubre de 2012 hasta febrero de 2013 por descompensación de su enfermedad y anemia asociada. En una de las hospitalizaciones se pesquisó dos pequeños nódulos pulmonares en el lóbulo inferior derecho. La biopsia pulmonar no arrojó resultados concluyentes. En la penúltima hospitalización (enero de 2013) se documentaron múltiples nódulos pulmonares en una TAC de tórax. El estudio microbiológico de las muestras obtenidas por fibrobroncoscopia, incluyendo cultivo de hongos, cultivo corriente y para micobacterias, resultó negativo. No se realizó videotoracoscopia por las malas condiciones del paciente. Al alta, se describió una pequeña lesión malar izquierda eritematosa para la cual se indicó tratamiento con amoxicilina. Tres semanas más tarde requirió una nueva hospitalización por progresión de la lesión malar comprometiendo una extensa zona de la hemicara izquierda, con áreas necróticas y supuradas, sensibilidad local y prurito; no se asociaba a adenopatías locales (Figuras 1 y 2). A pesar de un tratamiento empírico con piperacilina/tazobactam y vancomicina, la lesión no mejoró. $\mathrm{Al} 4^{\circ}$ día de evolución, el paciente presentó 
Tabla 1. Resumen de las manifestaciones clínicas, tratamiento y desenlace de 3 pacientes con infecciones criptocócicas, sin infección por VIH asociada

\begin{tabular}{|c|c|c|c|}
\hline Parámetro & Caso 1 & Caso 2 & Caso 3 \\
\hline Sexo, edad (años) & Femenino, 69 & Femenino, 49 & Masculino, 58 \\
\hline Enfermedad de base & $\begin{array}{l}\text { Vasculitis renal } \\
\text { Falla renal }\end{array}$ & $\begin{array}{l}\text { Trasplante renal } \\
\text { Diabetes mellitus II } \\
\text { Falla renal }\end{array}$ & Cirrosis hepática Child C, desnutrición \\
\hline Inmunosupresión & Prednisona 10 mg/día + azatriopina & $\begin{array}{l}\text { Prednisona } 10 \text { mg/día, micofenolato, } \\
\text { tacrolimus }\end{array}$ & $\begin{array}{l}\text { CAIDS (cirrhosis-associated immune } \\
\text { dysfucntion syndrome) }\end{array}$ \\
\hline Manifestación clínica & $\begin{array}{l}\text { Fiebre, cefalea y compromiso de } \\
\text { conciencia fluctuante }\end{array}$ & Fiebre y cefalea continua & Lesión cutánea \\
\hline Estudio citoquímico y lugar & LCR: normal & $\begin{array}{l}\text { LCR: proteinorraquia, hipoglucorraquia, } \\
\text { pleocitosis mononuclear }\end{array}$ & $\begin{array}{l}\text { Líquido ascítico } \\
\text { Aumento de proteínas con } \\
\text { pleocitosis mononuclear }\end{array}$ \\
\hline Sitios de cultivos $(+)$ o presencia histológica & LCR & LCR & Líquido ascítico, piel \\
\hline Tinta China & + & + & + \\
\hline Antígeno C. neoformans & No disponible & + en LCR & No solicitado \\
\hline Estudio de imágenes SNC & Normal & Hidrocefalia, infarto cerebral & No aplicable \\
\hline Laboratorio-otros & Hiponatremia & Hiponatremia, ADA elevado en LCR & Hiponatremia \\
\hline Diagnóstico final & Meningoencefalitis criptocócica & Meningoencefalitis criptocócica & Criptococcosis diseminada \\
\hline Días desde ingreso a inicio tratamiento & 21 & 39 & No iniciado \\
\hline Días de tratamiento y compuesto & 2 & 23 (anfotericina+fluconazol) & 0 \\
\hline Desenlace & Fallece & Fallece & Fallece \\
\hline Causa de muerte & $\begin{array}{l}\text { Muerte cerebral post paro } \\
\text { cardiorespiratorio }\end{array}$ & Shock séptico & Disfunción multiorgánica \\
\hline
\end{tabular}

deterioro clínico con compromiso de conciencia, falla renal y shock, requiriendo ingreso a UTI. Se efectuó una biopsia de la lesión malar. El estudio citoquímico del líquido ascítico mostró un recuento de 500 céls $/ \mu \mathrm{L}$ de predominio mononuclear (70\%), glucosa de $57 \mathrm{mg} /$ $\mathrm{dL}$, proteínas de $3,5 \mathrm{~g} / \mathrm{dL}$ con estudio negativo para

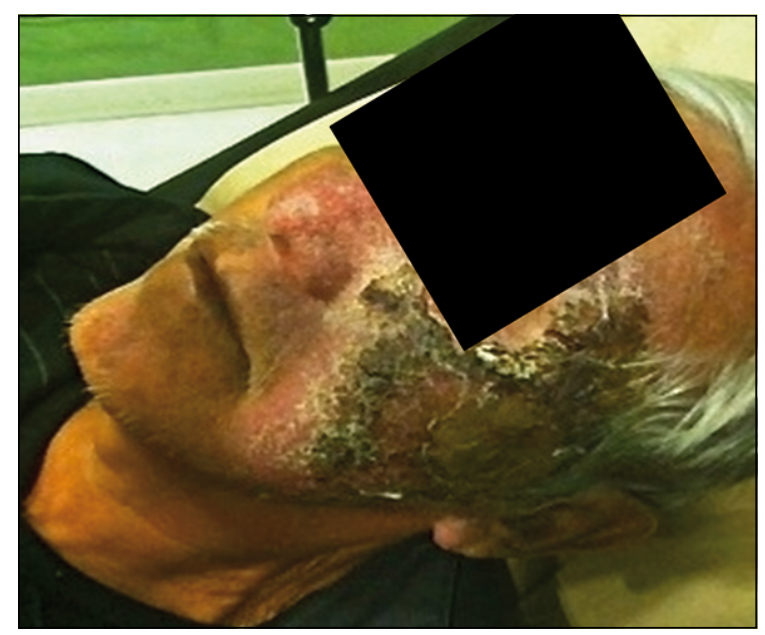

Figura 1. Lesión malar con placa indurada necrótica. micobacterias. La tinta china, el cultivo en frasco de hemocultivo y en placa de agar chocolate del líquido ascítico demostraron presencia de C. neoformans (al segundo y tercer día de cultivo, respectivamente) los que fueron recibidos antemortem. La biopsia de la lesión facial mostró múltiples levaduras libres y en cúmulos

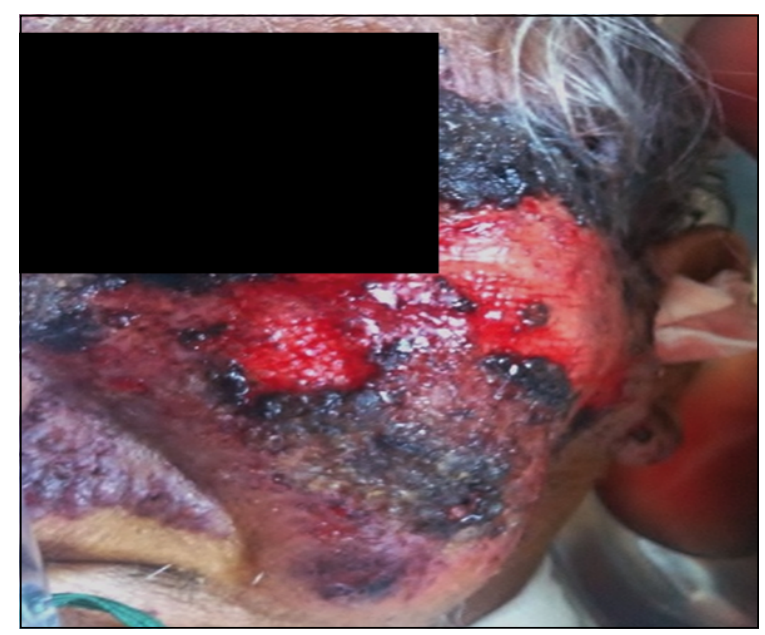

Figura 2. Lesión malar luego remoción parcial placa necrótica. 
Figura 3. Levaduras libres y en cúmulos en el intersticio (tinción de Grocott con amplificación 40x)

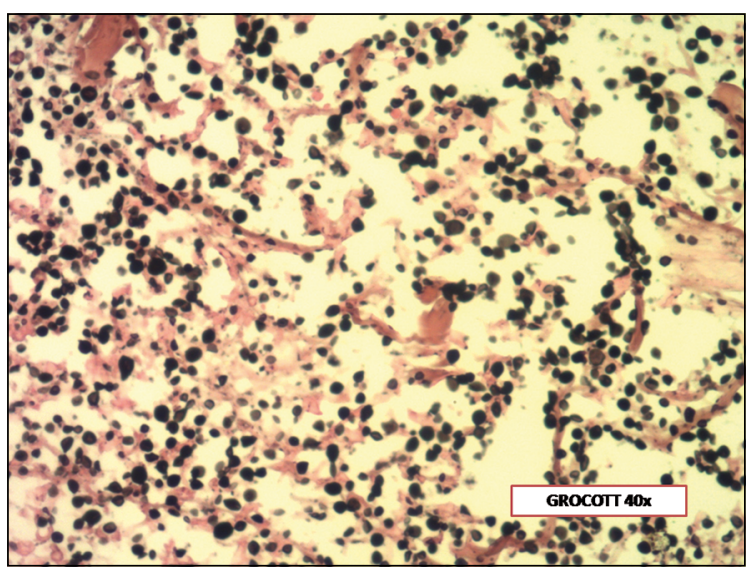

en el intersticio (Figura 3 para la tinción de Grocott con amplificación 40x). Falleció a los 10 días de haber ingresado.

\section{Discusión}

El género Cryptococcus está integrado por varias especies de levaduras capsuladas asociándose la mayor parte de las infecciones en seres humanos a dos especies capaces de crecer a $37^{\circ} \mathrm{C}$ : C. neoformans y $C$. gattii. El primero de ellos puede ser subtipificado según los serotipos capsulares en cuatro grupos (A-D) y algunos han propuesto separar como nuevas especies al serotipo D como C. neoformans y al serotipo A como C. grubii, aunque la utilidad clínica de esta separación no es aún evidente $^{3,4}$. La distinción entre $C$. neoformans y $C$. gattii puede ser efectuada por serotipificación, estando los serotipo $\mathrm{B}$ y $\mathrm{C}$ asociados a $C$. gattii, por pruebas bioquímicas especiales o métodos moleculares ${ }^{4}$. A pesar de que en nuestros casos no se contó con estas herramientas, la probabilidad de infecciones por C. gattii es baja debido a que son infrecuentes, se asocian principalmente a climas tropicales o subtropicales y son observadas también en pacientes inmunocompetentes ${ }^{4,5}$.

En este reporte se presentan tres casos de criptocosis que afectaron a pacientes adultos inmunodeprimidos sin infección por VIH/SIDA, entre los años 2007 y 2012, en un hospital general. Dos casos correspondieron a infección meníngea y uno a infección diseminada. En la literatura científica nacional sólo existe un reporte previo sobre una infección articular por C. neoformans, en un adulto mayor inmunocompetente ${ }^{6}$. El hecho de que los tres casos que presentamos en esta serie hayan sido recolectados en cinco años en un hospital en Chile, subraya la baja frecuencia de este tipo de infecciones en pacientes sin infección por VIH.

Cryptococcus neoformans es una levadura capsulada, oportunista y de amplia distribución mundial. Causa enfermedades en escenarios clínicos asociados a un intenso inmunocompromiso, especialmente de tipo celular. Ha sido mayormente descrita en pacientes con infección por VIH/SIDA y, en menor grado, en otras condiciones con inmunosupresión tales como neoplasias hematológicas o tumores sólidos, trasplantes, diabetes mellitus, cirrosis hepática, falla renal, colagenopatías o uso de corticoesteroides ${ }^{7-11}$. Los sitios anatómicos más afectados corresponden a pulmón y meninges. Luego de la exposición al hongo en el ambiente, (asociado a deyecciones de aves), éste es inhalado por el hospedero, anidándose en los sitios blanco, con o sin diseminación hematógena ${ }^{6}$. La infección pulmonar suele ser más frecuente en pacientes con patología pulmonar crónica y, la del SNC, en pacientes con disfunción de órganos ${ }^{11}$. La infección puede evolucionar hacia una forma diseminada comprometiendo dos o más sitios. Esto ocurre especialmente en pacientes con cirrosis hepática, diabetes mellitus o enfermedad autoinmune en terapia inmunosupresora ${ }^{7,8}$.

Las características compartidas en los tres casos bajo análisis incluyen el diagnóstico tardío o ausencia de sospecha clínica y la elevada letalidad. En términos globales, la falta de sospecha se explica por la baja frecuencia de este microorganismo como agente oportunista en pacientes en terapia inmunosupresora o con cirrosis hepática. Sólo estudios multicéntricos efectuados en países desarrollados ha permitido contar con casuísticas elevadas que entregan información sobre las manifestaciones clínicas y la respuesta al tratamiento ${ }^{11}$. La baja frecuencia de esta infección en pacientes sin infección por VIH/SIDA $(0,4$ a 5 casos por millón de habitantes) dificulta su reconocimiento clínico o la sospecha precoz por parte de los equipos tratantes ${ }^{10}$. La baja sospecha hace que no se incorporen al estudio de infecciones del SNC, el cultivo de hongos, la tinción con tinta China y la detección de antígeno en el LCR. Esta levadura puede ser reconocida en un cultivo especializado y, dependiendo del inóculo, requerir hasta cinco días de incubación; tal como fue observado en el caso 1 (positivo al cuarto día). El test de la tinta china permite un diagnóstico rápido, es fácil de realizar y de bajo costo, pero tiene baja sensibilidad (supera levemente el 50\%) no permitiendo descartar el diagnóstico en pacientes inmunodeprimidos sin infección por VIH. En contraste, la detección del antígeno de C. neoformans en LCR y suero es un test rápido y de alta sensibilidad, pero tiene restricciones de costo y disponibilidad. El 97\% de los pacientes tiene al menos una de estas tres pruebas positivas ${ }^{11}$. En nuestros dos casos de infección del SNC, la baja frecuencia epidemiológica, la falta de sospecha clínica, el lento crecimiento del hongo en el cultivo y un estudio inicial que no incluyó la búsqueda de este hongo, contribuyeron al diagnóstico y tratamiento tardío, lo que resalta la importancia de comunicar esta experiencia. 
En uno de estos casos además, el hallazgo de valores elevados de ADA en el LCR hizo plantear el diagnóstico de TBC meníngea a pesar de las pruebas moleculares negativas. En un país como Chile, con cifras persistentes de TBC, bajo rendimiento de la baciloscopia en el LCR, lentitud del cultivo de Koch en medios convencionales y bajas probabilidades de diagnósticos alternativos, el hallazgo de un valor ADA elevado sobre el nivel de corte sugerente ( 25 vs $7 \mathrm{UI} / \mathrm{L}$ ), fue interpretado como una clave diagnóstica para justificar el tratamiento para TBC por el equipo tratante. La especificidad de un valor ADA elevado para TBC es cercana a $90 \%$ pero este parámetro puede ser menor en escenarios con declinación de la TBC. Causas alternativas de esta elevación son linfomas, neurosífilis, infección por citomegalovirus, lupus eritematoso sistémico con compromiso del SNC y, ciertamente, meningitis por C. neoformans ${ }^{12}$.

Las manifestaciones clínicas de aquellos pacientes sin infección por VIH/SIDA con compromiso meníngeo difieren en parte a los del grupo con infección retroviral. Los pacientes son de mayor edad (unas dos décadas de diferencia), con más pleocitosis y proteinorraquia en el LCR (mediana 43 vs $3 / \mu \mathrm{L}$ y 111 vs $59 \mathrm{mg} / \mathrm{dL}$, respectivamente), menor frecuencia de hemocultivos positivos para esta levadura (35 vs 67\%) y mayor porcentaje con anomalías detectadas en el estudio de imágenes del SNC ( 87 vs 56\%), las cuales incluyen refuerzo meníngeo, infarto cerebral, hidrocefalia o abscesos ${ }^{13}$. Uno de nuestros casos presentó esta constelación de manifestaciones, pero en el otro destacó la ausencia (caso 1) de las mismas, contribuyendo a la baja sospecha clínica. En pacientes con inmunosupresión celular, sea por corticosteroides, receptores de trasplante o linfoma, el cuadro de meningitis es más atípico e indolente que en pacientes nefrópatas, diabéticos o cirróticos. Se observa menor frecuencia de cefalea, de compromiso sensorial inicial, signos meníngeos o pleocitosis, haciendo el diagnóstico más difícil ${ }^{14}$. Un aspecto común en nuestros casos es la aparición de hiponatremia en la evolución de la enfermedad, un rasgo descrito tanto en pacientes con o sin infección por VIH/SIDA ${ }^{13}$.

El tratamiento de las infecciones meníngeas por $C$. neoformans en pacientes sin infección por VIH/SIDA está basado en las lecciones aprendidas en la pandemia del SIDA que recomienda el uso de anfotericina B con fluocitosina en la fase de inducción y que, a pesar del tratamiento, tienen una mortalidad entre 15 y $45 \%^{13,15-18}$. Fluconazol es aplicado como un compuesto en la fase de consolidación o acompañando a anfotericina $\mathrm{B}$ en la fase de inducción, pero rara vez como monoterapia en la primera fase del tratamiento ${ }^{11,17,18}$. Fluocitosina es un compuesto de difícil acceso y por ello rara vez usado en Chile como fármaco asociado. Por su parte, anfotericina B desoxicolato puede exponer a los pacientes con vasculitis renal o cirrosis hepática, como los de nuestra serie, al riesgo de nefrotoxicidad lo que hace difícil seguir esta recomendación. Anfotericina B en formulaciones lipídicas podría ser usado por su mayor seguridad renal y es, de hecho, recomendado en el tratamiento de infecciones criptocócicas del SNC en pacientes con trasplante de órganos sólidos, pero su alto costo limita su aplicabili$\mathrm{dad}^{18}$. Es posible que voriconazol represente una mejor alternativa en ambas fases del tratamiento debido a su buena penetración al SNC, su mayor actividad sobre $C$. neoformans en comparación a fluconazol $\left(\mathrm{CIM}_{90} 0,12 \mathrm{a}\right.$ $0,25 \mathrm{vs} 8-16 \mu \mathrm{g} / \mathrm{ml}$, respectivamente) y la existencia de varios reportes de eficacia en condiciones extremas ${ }^{19,20}$. $\mathrm{Su}$ introducción después de la progresiva desaparición de casos observada en los países desarrollados con la llegada de la terapia anti-retroviral explica la falta de investigaciones comparativas en este escenario. Así, posibles diferencias en eficacia y seguridad entre ambos compuestos requieren de nuevos estudios comparativos. En concordancia con estos problemas, en nuestros pacientes con infección meníngea se utilizaron diferentes compuestos antifúngicos.

La sospecha tardía y, en consecuencia, el inicio de un tratamiento varios días después del ingreso, es un fenómeno previamente descrito en pacientes sin infección por VIH/SIDA (9,5 vs 2,6 días desde el ingreso $)^{13}$. En series comparativas no randomizadas, la mortalidad es similar entre ambos grupos de pacientes y los factores independientes asociados a ella incluyen leucocitosis al ingreso, un mayor score de co-morbilidad de Charlson, lesiones del SNC en el estudio de imágenes, disfunción de algún órgano, edad $\geq 60$ años o neoplasia hematológica $^{11,13}$. En nuestra pequeña serie se pudieron identificar algunos de estos factores como por ejemplo, la edad mayor, la disfunción de un órgano y la presencia de daño estructural en el SNC.

Las intervenciones neuroquirúrgicas con la instalación de una derivación ventricular debido a hidrocefalia como en el caso 2, forman parte del escenario terapéutico en cerca de $10 \%$ de estos pacientes ${ }^{11}$. Al menos la mitad de los pacientes presenta aumento de la presión intracraneal (>200 $\mathrm{mm} \mathrm{H}_{2} \mathrm{O}$ ) y cerca de $20 \%$ requiere procedimientos para bajarla, ya sea con punciones lumbares diarias que permitan reducir en $50 \%$ la presión inicial hasta obtener cifras normales, o derivación ventricular externa o interna. La terapia farmacológica con corticosteroides, acetazolamida o manitol no ha sido efectiva en estos $\operatorname{casos}^{11,17,18}$.

La dosis de corticosteroides en los dos primeros casos fue relativamente baja y no considerada sobre el umbral para infecciones oportunistas. El efecto inmunosupresor es proporcional a la dosis utilizada por vía sistémica. Se considera que el riesgo de infecciones oportunistas se incrementa cuando la dosis acumulada de prednisona supera los $700 \mathrm{mg}$ para pacientes con inicio reciente o cuando la dosis diaria es $>10-15 \mathrm{mg}$ en aquellos con 
tratamiento crónico ${ }^{21,22}$. La depleción de linfocitos CD4 por corticosteroides es dosis dependiente, no existiendo reportes de recuentos menores de $250 / \mathrm{mm}^{3}$ con dosis equivalente de prednisona $\leq 10 \mathrm{mg} / \mathrm{día}^{21}$. De esta manera, el uso concomitante de otros inmunosupresores o de co-morbilidades asociadas, fue relevante en nuestros pacientes para el desarrollo de la infección oportunista.

Uno de nuestros casos se asoció a una infección diseminada por una lesión necrótica facial progresiva, peritonitis fúngica y quizás, nódulos pulmonares criptocócicos en un paciente con cirrosis hepática. En pacientes sin infección por VIH/SIDA, la cirrosis hepática aparece como uno de los principales factores de riesgo para infección diseminada por esta levadura, caracterizándose por una mortalidad que bordea el $80 \%{ }^{7,8,23}$. Se manifiesta predominantemente como peritonitis espontánea. Este agente debe ser sospechado en pacientes con ascitis neutrocítica con cultivo corriente negativo, por lo que se debe considerar el tardío desarrollo de la levadura en los cultivos. Produce una peritonitis con pleocitosis moderada de predominio polimorfonuclear o mononuclear como en nuestro paciente, la que en la mayor parte es reconocida antemortem $^{23}$. Otros sitios de infección en el paciente con daño hepático avanzado incluyen $\mathrm{SNC}$, luego piel y tejidos blandos. Un cuadro de celulitis progresiva con componente necrótico y ulceración que no responde a antibioterapia en un paciente con cirrosis podría ayudar en la sospecha clínica. El tratamiento es problemático debido a la dificultad para usar triazoles en pacientes con disfunción hepática, dejando a anfotericina $\mathrm{B}$ como alternativa ${ }^{23}$. Los pacientes con cirrosis hepática están inmunosuprimidos y son susceptibles a infecciones. Algunos autores han acuñado el concepto CAIDS (cirrhosis-associated immune dysfunction syndrome) como un estado multifactorial de disfunción inmune sistémica ${ }^{24}$.

Paradójicamente, en nuestro hospital las infecciones por $C$. neoformans sólo han sido detectadas en pacientes sin infección VIH, sin tener registro por laboratorio de casos en pacientes con esta infección viral. Así, en ninguno de los 27 pacientes con infección por VIH que ingresaron a la Unidad de Pacientes Críticos entre el año 2005 y 2013 debido a un cuadro infeccioso, se detectó algún evento por esta levadura (manuscrito en preparación).

\section{Conclusiones}

Los tres casos incluidos en esta serie ilustran nuevos escenarios para las infecciones por $C$. neoformans, una levadura históricamente asociada a pacientes con infección por VIH/SIDA. Los casos comentados representan condiciones de inmunosupresión por diferentes causas y lo pleomórfico, y a veces sutil, de la presentación clínica de infección por este hongo. En nuestros pacientes las manifestaciones incluyeron cefalea, incluso fluctuante, con LCR normal, y en el otro extremo, una lesión cutánea progresiva con desarrollo de necrosis y sin respuesta a tratamiento antimicrobiano convencional. La serie subraya también la alta sospecha que se debe tener en estos pacientes y la necesidad de solicitar un estudio microbiológico oportuno y adecuado. La alta letalidad de estas infecciones se explica por su tardío reconocimiento y condiciones de base.

\section{Resumen}

La mayoría de los casos de infecciones criptocócicas se presenta en pacientes con infección por VIH/SIDA con inmunosupresión avanzada. En otro tipo de pacientes inmunosuprimidos es menos conocida, pero ha ido aumentando en frecuencia. Presentamos tres casos de infecciones criptocócicas en pacientes inmunosuprimidos no infectados por VIH, que se manifestaron como meningitis en un receptor de trasplante renal y en un paciente con terapia corticosteroidal y una infección cutánea progresiva necrótica con diseminación secundaria en un paciente con cirrosis hepática avanzada. En todos los casos, la infección fue identificada tardíamente. La infección en el paciente con cirrosis se estableció postmortem. Las infecciones criptocócicas en pacientes sin infección por VIH pueden ocurrir en diferentes sitios, se sospechan tardíamente y tienen alta letalidad.

\section{Referencias bibliográficas}

1.- Silva M M. Neurologic complications of HIV in the HAART era: where are we? Braz J Infect Dis 2012; 16: 373-8.

2.- Amâncio F F, Lambertucci J R, Cota G F, Antunes C M. Predictors of the short-and longterm survival of HIV-infected patients admitted to a Brazilian intensive care unit. Int J STD AIDS 2012; 23: 692-7.

3.- Howell S A, Hazen K C. Chapter 115: Candida, Cryptococcus, and other yeasts of medical importance. En: Versalovic J, Carroll C K, Funke G, Jorgensen J H, Landry M L, Warnock D W, eds. Manual of Clinical Microbiology, $10^{\text {th }}$ Ed. Washington, DC: ASM Press; 2011, p. 1793-821.

4.- Perfect J R. Chapter 263: Cryptococcus neoformans. En: Mandell GL, Bennett JE, Dolin R, eds. Mandell, Douglas, and Bennett's Principles and Practices of Infectious Diseases, $7^{\text {th }}$ Ed. Philadelphia, PA: Churchill Livingstone Elsevier; 2010, p. 3287-303.

5.- Smith R M, Mba-Jonas A, Tourdjam M,
Shimek T, DeBess E, Marsden-Haug N, et al. Treatment and outcomes among patients with Cryptococcus gattii infections in the United States pacific northwest. Plos One 2014; 9: e88875.

6.- Gil L G, Foster B C, Neira Q O, Palma C S, Basualdo A J, Heredia P C, et al. Artritis por Cryptococcus neoformans en un adulto mayor: Presentación de un caso y revisión. Rev Chilena Infectol 2006; 23: 330-5.

7.- $\quad$ Chuang Y M, Ho Y C, Chang H T, Yu C J, Yang P C, Hsueh P R. Disseminated 
cryptococcosis in HIV-uninfected patients. Eur J Clin Microbiol Infect Dis 2008; 27: 307-10.

8.- França A V, Carneiro M, dal Sasso K, Souza Cda S, Martinelli A. Cryptococcosis in cirrhotic patients. Mycoses 2005; 48: 68-72.

9.- Husain S, Wagener M M, Singh N. Cryptococcus neoformans infection in organ transplant recipients: variables influencing clinical characteristics and outcome. Emerg Infect Dis 2001; 7: 375-81.

10.- Mirza S A, Phelan M, Rimland D, Graviss E, Hamill R, Brandt M E, et al. The changing epidemiology of cryptococcosis: An uptade from population-based active surveillance in 2 large metropolitan areas, 1992-2000. Clin Infect Dis 2003; 36: 789-94.

11.- Pappas P G, Perfect J R, Cloud G A, Larsen R A, Pankey G A, Lancaster D J, et al. Cryptococcosis in human immunodeficiency virus-negative patients in the era of effective azole therapy. Clin Infect Dis 2001; 33: 690-9.

12.- Lasso M. Meningitis tuberculosa: claves para su diagnóstico y propuestas terapéuticas. Rev Chilena Infectol 2011; 28: 238-47.

13.- Lee Y C, Wang J T, Sun H Y, Chen Y C. Comparisons of clinical features and mortality of cryptococcal meningitis between patients with and without human immunodeficiency virus infection. J Microbiol Immunol Infect 2011; 44: 338-45.

14.- Shih C C, Chen Y C, Chang S C, Luh K T, Hsieh WC. Cryptococcal meningitis in nonHIV-infected patients. Q J Med 2000; 93: 245 51.

15.- Bennett J E, Dismukes W E, Duma R J, Medoff G, Sande M A, Gallis H, et al. A comparison of amphotericin $\mathrm{B}$ alone and combined with fluocytosine in the treatment of cryptococcal meningitis. N Engl J Med 1979; 30: 126-31.

16.- Larsen R A, Leal M A, Chan L S. Fluconazole compared with amphotericin B plus flucytosine for cryptococcal meningitis in AIDS. A randomized trial. Ann Intern Med 1990; 113: 183-7.

17.- Saag M S, Graybill R J, Larsen R A, Pappas P G, Perfect J R, Powderly W G, et al. Practice guidelines for the management of cryptococcal disease. Clin Infect Dis 2000; 30: 710-8.

18.- Perfect J R, Dismukes W E, Dromer F, Goldman D L, Graybill J R, Hamill R J, et al. Clinical practice guidelines for the management of cryptococcal disease: 2010 update by the Infectious Diseases Society of America. Clin Infect Dis 2010; 50: 291-322.

19.- Johnson L B, Kaufmann C A. Voriconazole: A new triazole antifungal agent. Clin Infect Dis 2003; 36: 630-7.

20.- Yong L. Voriconazole: may be an option for treatment of cryptococcal meningitis. Med Mycol 2011; 49: 335.

21.- Gluck T, Kiefmann B, Grohmann M. Immune status and risk for infection in patients receiving chronic immunosuppressive therapy. J Rheumatol 2005; 32: 1473-80.

22.- Stuck A E, Minder C E, Frey F J. Risk of complications in patients taking glucocorticosteroids. Rev Infect Dis 1989; 11: 954-63.

23.- Singh N, Husain S, de Vera M, Gayowski T, Cacciarelli T V. Cryptococcus neoformans infection in patients with cirrhosis, including liver transplant candidates. Medicine 2004; 83 : 188-92.

24.- Bonnel A R, Bunchorntavakul C, Reddy K R. Immune dysfunction and infections in patients with cirrhosis. Clin Gastroenterol Hepatol 2011; 9: 727-38. 